\title{
Deuterium as a Stereochemically Invisible Blocking Group for Chiral Ligand Synthesis
}

\author{
Ross A. Arthurs and Christopher J. Richards* \\ School of Chemistry, University of East Anglia, Norwich Research Park, Norwich, NR4 7TU, U.K. \\ Supporting Information Placeholder

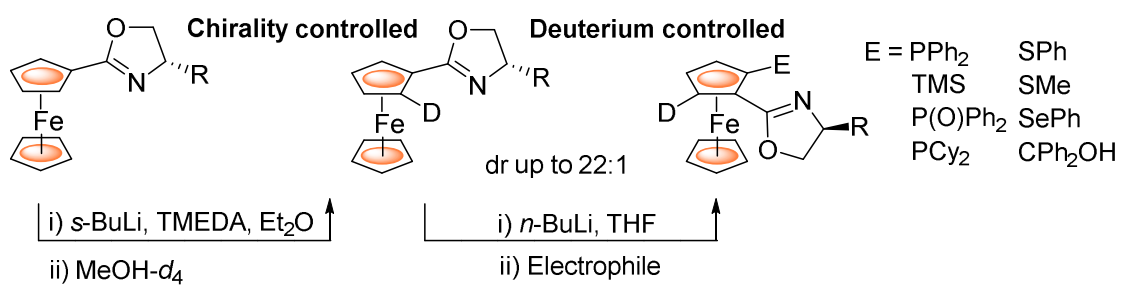

\begin{abstract}
Highly diastereoselective lithiation ( $s$-BuLi/TMEDA in $\left.\mathrm{Et}_{2} \mathrm{O},-78^{\circ} \mathrm{C}, 2 \mathrm{~h}\right)$ of $(S)$-2-ferrocenyl-4(substituted)oxazolines followed by addition of $\mathrm{MeOH}-d_{4}$, gave up to $95 \% \mathrm{D}$ incorporation. Subsequent application of alternative lithiation conditions ( $n$-BuLi in THF, $-78^{\circ} \mathrm{C}, 2 \mathrm{~h}$ ), followed by addition of an electrophile, resulted in a reversal of diastereoselectivity controlled primarily by the high $k_{\mathrm{H}} / k_{\mathrm{D}}$ value for lithiation (isomer ratio typically between 10:1 and 20:1).
\end{abstract}

Many non-racemic ligands employed in metal catalyzed asymmetric reactions contain more than one element of chirality. For a $C_{1}$-symmetric ligand containing two such elements, diastereoisomers are possible which may result in different reaction product enantioselectivities, and there are a number of examples where the identification of matched and mismatched chirality pairings has been established. ${ }^{1}$ In most cases, however, ligand diastereoisomers are not explored in catalysis, not least because they are commercially unavailable and/or are difficult to synthesize.

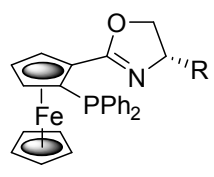

$\left(S, S_{p}\right)$-1a-e

$$
\begin{aligned}
& \text { a }(\mathrm{R}=i-\mathrm{Pr}) \\
& \text { b }(\mathrm{R}=t-\mathrm{Bu}) \\
& \text { c }(\mathrm{R}=\mathrm{Me}) \\
& \text { d }\left(\mathrm{R}=\mathrm{CH}_{2} i-\mathrm{Pr}\right)
\end{aligned}
$$$$
\text { e }(R=P h)
$$

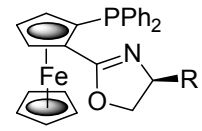

$\left(S, R_{\mathrm{p}}\right)$-2a-e
Figure 1. Phosphinoferrocenyloxazoline ligand diastereoisomers $\mathbf{1}$ and $\mathbf{2}$.

For example, $i$-Pr and $t$-Bu containing $\left(S, S_{\mathrm{p}}\right)-\mathbf{- 1 a} / \mathbf{b}$ are two frequently used and commercially available ferrocene-based P-N ligands (Figure 1 ). ${ }^{2}$ Both are generated by highly diastereoselective lithiation of a ferrocenyloxazoline precursor $^{3}$ followed by introduction of the diphenylphosphine moiety using $\mathrm{Ph}_{2} \mathrm{PCl}$, methodology that has been applied also to the synthesis of $\left(S, S_{\mathrm{p}}\right)$ 1c-e. The diastereoisomers $\left(S, R_{\mathrm{p}}\right)$-2a-c have been synthesized by use of a removable TMS blocking group, lithiation and phosphine introduction then occurring at the other $\alpha$-position. ${ }^{2 c}$ There are a small number of re- ports on the use of ligands $\mathbf{2 a} / \mathbf{b}$ in catalysis, ${ }^{4}$ including instances where these are the matched diastereoisomer. ${ }^{4 \mathrm{~g}}$

An alternative to the use of a TMS blocking group is to employ the additive di-tert-butyldiglyme [ $(t-\mathrm{Bu})_{2}$-DGME] which reverses the selectivity of lithiation ( $\mathrm{dr}$ up to $6: 1$ in a study which employed MeSSMe as the electrophile, $\mathrm{R}=$ $i$-Pr, Me). ${ }^{5}$ This methodology should permit the direct synthesis of $\mathbf{2 a}$ and $\mathbf{2}$ by use of $\mathrm{Ph}_{2} \mathrm{PCl}$ as the electrophile. The practicality of this procedure is however restricted by the low yield ( $28 \%$ ) reported for the synthesis of commercially unavailable $(t-\mathrm{Bu})_{2}$-DGME. In addition, no diastereoselectivity resulted with $(t-\mathrm{Bu})_{2}$-DGME on lithiation of the $t$-Bu oxazoline precursor to $\mathbf{1 b} / \mathbf{2} \mathbf{b}$, and the application of this procedure to the $\mathrm{CH}_{2} i-\mathrm{Pr}$ and $\mathrm{Ph}$ oxazoline precursors to $\mathbf{1 d} / \mathbf{2} \mathbf{d}$ and $\mathbf{1 e} / \mathbf{2 e}$, respectively, has not been reported.

In this Letter we describe an alternative approach to access these largely unexplored ligand diastereoisomers in just two steps. This exploits the very high primary kinetic isotope effect reported for C-D vs. C-H lithiation, for which values of $k_{\mathrm{H}} / k_{\mathrm{D}}$ in excess of 50 are known. ${ }^{6}$ This effect has been exploited to aid the control of reaction selectively (chemoselectivity, regioselectivity and enantioselectivity), ${ }^{7}$ but examples of changes in diastereoselectivity appear to be rare. ${ }^{8}$ Herein we report on the reversal of lithiation selectivity for diastereoisomer ligand synthesis, following introduction of deuterium, by exploitation of high values of $k_{\mathrm{H}} / K_{\mathrm{D}}$.

The application of a deuterium blocking group to the selective generation of a diastereoisomer requires that 
conditions exist for both the highly selective and poorly/non-selective lithiation of the starting substrate. Then in the first instance lithiation followed by the addition of a deutero acid will result in the highly selective introduction of deuterium. In the second instance the deuterium will principally control the position of lithiation to give the alternative diastereoisomer with high selectivity, following addition of the electrophile. As already inferred, $(S)$-valinol-derived ferrocenyloxazoline $(S)$-za meets these requirements, as lithiation selectivity is highly dependent upon the solvent and additive employed. High diastereoselectivity results when a diethyl ether solution is treated at low temperature with $s$-BuLi in the presence of TMEDA. ${ }^{3}$ Repetition of these conditions (conditions A) followed by the addition of trimethylsilylchloride resulted in the essentially exclusive $(>100: 1)$ formation of $\left(S, S_{\mathrm{p}}\right)-\mathbf{4 a}$ (Scheme 1). In contrast, use of $n$-BuLi in THF at low temperature (conditions B), followed by addition of trimethylsilylchloride, resulted in a $2: 1$ ratio of diastereoisomeric products due to the significant formation of $\left(S, R_{\mathrm{p}}\right)$-5a.

Scheme 1. High and low selectivity for the lithiation and subsequent trimethylsilylation of $(S)$-za.

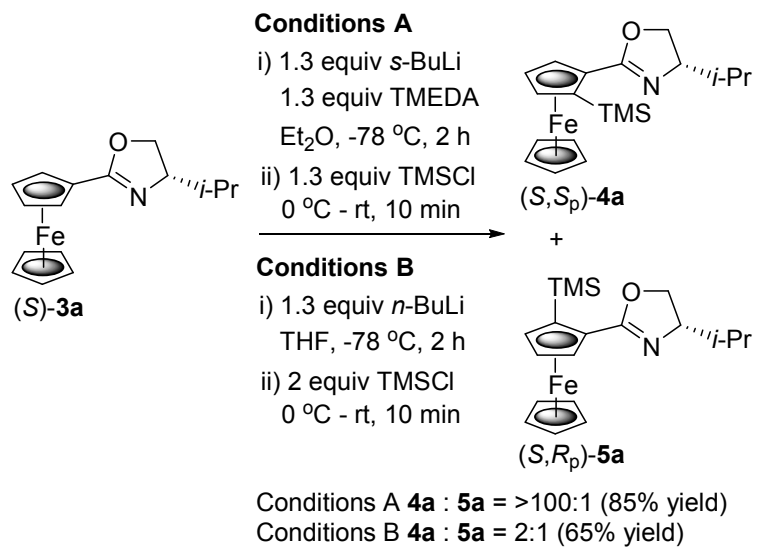

Scheme 2. Synthesis of $\left(S, R_{\mathrm{p}}\right)-5-d-5 \mathbf{a}-\mathbf{d}$ by deuterium directed reversal of diastereoselectivity.

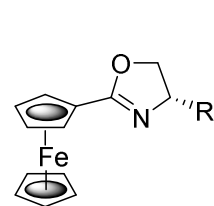

(S)-3a-d
Conditions A

1.3 equiv TMEDA $\mathrm{Et}_{2} \mathrm{O},-78^{\circ} \mathrm{C}, 2 \mathrm{~h}$

ii) 1.5 equiv $\mathrm{MeOH}-\mathrm{d}_{4}$

$0^{\circ} \mathrm{C}-\mathrm{rt}, 10 \mathrm{~min}$

$\left(S, R_{\mathrm{p}}\right)-2-d-3 a-d$
Conditions B

i) 1.3 equiv $n$-BuLi THF, $-78^{\circ} \mathrm{C}, 2 \mathrm{~h}$

ii) 1.5 equiv $\mathrm{TMSCl}$ $0^{\circ} \mathrm{C}-\mathrm{rt}, 10 \mathrm{~min}$

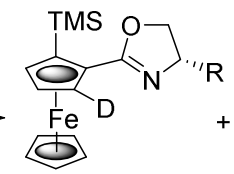

$\left(S, R_{\mathrm{p}}\right)-5-d-5 \mathbf{a}-\mathbf{d}$
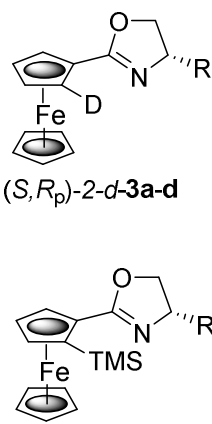

$\left(S, S_{p}\right)-\mathbf{4 a - d}$
These high and low lithiation stereoselectivities, together with the use of deuterium, were used to bring about an overall reversal in the stereochemistry of $\alpha$ silylation (Scheme 2). Lithiation under conditions A, followed by the addition of methanol- $d_{4}$, gave $\left(S, R_{\mathrm{p}}\right)-2-d-\mathbf{z a}^{9}$ in which only a single cyclopentadienyl $\alpha$-hydrogen was deuterated, with a percentage incorporation of $94 \%$ as determined by ${ }^{1} \mathrm{H}$ NMR spectroscopy (Table 1 , entry 1 ). Subsequent application of lithiation conditions $\mathrm{B}$ to $\left(S, R_{\mathrm{p}}\right)-2-d-3 \mathrm{a}, \quad$ followed by addition of trimethylsilylchloride, resulted in the formation of $\left(S, R_{\mathrm{p}}\right)$ $5^{-} d-5$ a as the major diastereoisomer in a ratio of $10: 1$ (Figure 2). Using the lithiation ratios determined from conditions B with both non-deuterated $(S)-3 a(2: 1)$ and deuterated $\left(S, R_{\mathrm{p}}\right)-\mathbf{2}-d-\mathbf{3 a}(\mathbf{1}: \mathbf{1 0})$, together with the percentage deuterium incorporation (94\%), gave a calculated value for $k_{\mathrm{H}} / k_{\mathrm{D}}$ of $\sim 20$.

Table 1. Synthesis of $\left(S, R_{\mathrm{p}}\right)-5-d-5$ a-d by deuterium directed reversal of diastereoselectivity.

\begin{tabular}{|c|c|c|c|c|}
\hline entry & $\begin{array}{c}\text { substrate } \\
\text { (R) }\end{array}$ & $\begin{array}{c}\left(S, R_{\mathrm{p}}\right)-\mathbf{2}-d- \\
\text { 3a-d } \\
\text { \%yield } \\
\left(\% \mathrm{D}^{a}\right)\end{array}$ & $\begin{array}{l}\text { ratio } \mathbf{5}^{\mathbf{a}-} \\
\mathbf{d}: \mathbf{4}^{\mathbf{a}-\mathbf{d}^{b}}\end{array}$ & $\begin{array}{l}\text { \%yield }{ }^{c} \\
\left(\% D^{a, d}\right)\end{array}$ \\
\hline 1 & $3 \mathbf{a}(i-\mathrm{Pr})$ & $95(94)$ & 10:1 & $78^{e}(98)$ \\
\hline 2 & $3 \mathbf{b}(t-\mathrm{Bu})$ & $95(90)$ & $2.3: 1$ & $41(94)$ \\
\hline 3 & 3c (Me) & $85(95)$ & 21:1 & $59^{e}(92)$ \\
\hline 4 & 3d $\left(\mathrm{CH}_{2} i-\mathrm{Pr}\right)$ & $93(95)$ & $17: 1$ & 49 (94) \\
\hline
\end{tabular}

${ }^{a}$ Determined by ${ }^{1} \mathrm{H}$ NMR spectroscopy $\left(500 \mathrm{MHz}, \mathrm{CDCl}_{3}\right.$ ). ${ }^{b}$ Determined before column chromatography. ${ }^{c}$ Determined after column chromatography $\left(\mathrm{SiO}_{2}\right)$. ${ }^{d}$ Of major isomer. ${ }^{e}$ Isolated as a single diastereoisomer.

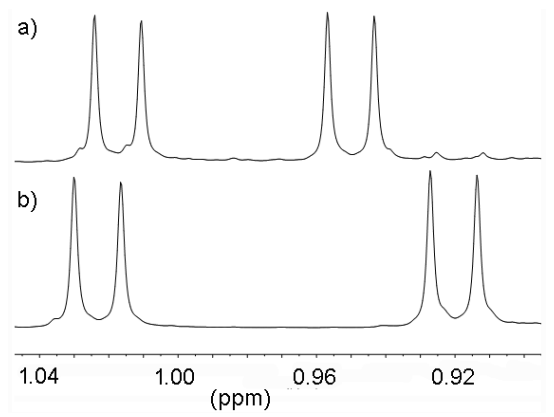

Figure 2. Reversal of diastereoselectivity. Part of the 500 $\mathrm{MHz}{ }^{1} \mathrm{H}$ NMR spectrum $\left(\mathrm{CDCl}_{3}, \mathrm{CH}\left(\mathrm{CH}_{3}\right)_{3}\right)$ of the unpurified product mixture arising from the reaction illustrated by: a) Scheme 2, conditions $B(R=i-P r)$, b) Scheme 1 , conditions A.

This sequence of reactions was also applied to oxazolines $\mathbf{3 b}$-d (Table $\mathbf{1}$, entries 2-4) resulting also in high overall diastereoselectivity for the methyl (3c) and iso-butyl (3d) substituted oxazolines, but in a reduced yield and modest diastereoselectivity for the tert-butyl derivative (3b). The latter result is likely due to the higher 
lithiation selectivity of this non-deuterated oxazoline under conditions B. ${ }^{10}$

The reversal in diastereoselectivity with deuterated ferrocenyloxazolines was extended to the synthesis of P-N ligands $\left(S, R_{\mathrm{p}}\right)-5$ - $d$-2a-d (Scheme 3, Table 2). These were formed as the major isomer when chlorodiphenylphosphine was used as the electrophile following lithiation under conditions $\mathrm{B}$, albeit in modest yield." Obtaining diastereomerically pure ligands by chromatographic separation proved challenging for these products (vide infra), but purification was readily achieved for $\left(S, R_{\mathrm{p}}\right)-{ }^{-}-d-\mathbf{2 a}$ and $\left(S, R_{\mathrm{p}}\right)-{ }^{-}-d-\mathbf{2 c}$ by recrystallization.

Scheme 3. Deuterium directed synthesis of $\left(S, R_{\mathrm{p}}\right)^{-5}-d-\mathbf{2 a}-$ d.

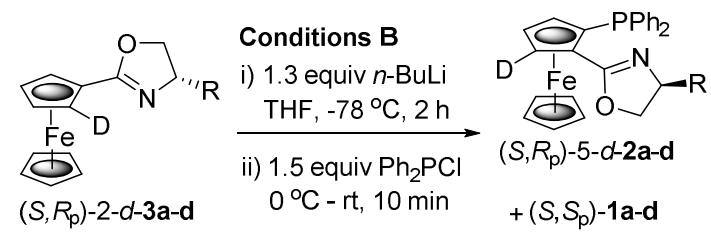

Table 2. Deuterium directed synthesis of $\left(S, R_{\mathrm{p}}\right)-5$ - $d$-2a-d.

\begin{tabular}{|c|c|c|c|c|}
\hline entry & $\begin{array}{c}\text { substrate }\left(S, R_{\mathrm{p}}\right)- \\
\text { 2-d-3a-d (R) }\end{array}$ & $\begin{array}{l}\text { sub- } \\
\text { strate } \\
\% D^{a}\end{array}$ & $\begin{array}{c}\text { ratio }\left(S, R_{\mathrm{p}}\right)- \\
5-d-\mathbf{2}:\left(S, S_{\mathrm{p}}\right)- \\
\mathbf{1}^{a, b}\end{array}$ & $\begin{array}{l}\text { \%yield }{ }^{b} \\
\left(\% \mathrm{D}^{a, c}\right)\end{array}$ \\
\hline 1 & $3 \mathbf{a}(\mathrm{R}=i-\mathrm{Pr})$ & 92 & $21: 1$ & $49^{d}(98)$ \\
\hline 2 & $3 \mathbf{b}(\mathrm{R}=t-\mathrm{Bu})$ & 90 & $2.5: 1$ & $50(98)$ \\
\hline 3 & $3 c(\mathrm{R}=\mathrm{Me})$ & 85 & $5: 1$ & $39^{e}(92)$ \\
\hline 4 & 3d $\left(\mathrm{R}=\mathrm{CH}_{2} i-\mathrm{Pr}\right)$ & 95 & $17: 1$ & $20(94)$ \\
\hline
\end{tabular}

${ }^{a}$ Determined by ${ }^{1} \mathrm{H}$ NMR spectroscopy (50o $\mathrm{MHz}, \mathrm{CDCl}_{3}$ ). ${ }^{b}$ Determined after column chromatography $\left(\mathrm{SiO}_{2}\right)$. ${ }^{c}$ Of major isomer. ${ }^{d}$ Isolated diastereomerically pure in $29 \%$ yield after recrystallization. ${ }^{e}$ Isolated diastereomerically pure in $36 \%$ yield after recrystallization.

Scheme 4. Reaction of $\left(S, R_{\mathrm{p}}\right)$-2-d-ze.

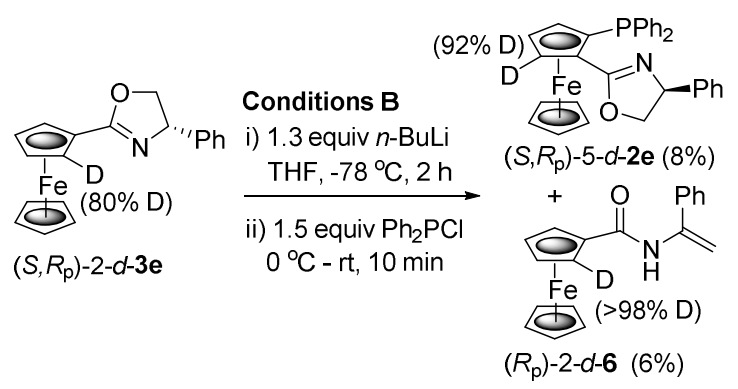

This methodology was also applied to the phenylsubstituted ferrocenyloxazoline 3e. Application of lithiation conditions A followed by addition of methanol$d_{4}$ resulted in $\left(S, R_{\mathrm{p}}\right)-\mathbf{2}-d_{-3} \mathbf{3}$ in $45 \%$ yield with a reasonable $(80 \%)$ level of deuterium incorporation. Subsequent application of the conditions $\mathrm{B} / \mathrm{PPh}_{2} \mathrm{Cl}$ protocol resulted in a mixture of products from which were isolated by column chromatography diastereomerically pure $\left(S, R_{\mathrm{p}}\right)$-5- $d$-2e and enamide $\left(R_{\mathrm{p}}\right)-\mathbf{2}-d-6$ (Scheme 4$)$. The latter likely arises from lithiation at position 4 of the oxazoline followed by ring-opening and nitrogen protonation on work-up, a process reported previously with another phenylsubstituted oxazoline substrate. ${ }^{12}$ Thus prevention of the favored lithiation pathway by deuterium introduction can lead to an undesirable reaction pathway, in addition to the formation of the alternative diastereoisomer.

The facility with which $i-\mathrm{Pr}$ containing ferrocenyloxazolines $(S)$-3a/ $\left(S, R_{\mathrm{p}}\right)-\mathbf{2}-d-\mathbf{3 a} \quad$ undergo lithiation led us to extend this methodology to the synthesis of a range of bidentate ligand diastereoisomers (Scheme 5, Table 3). Use of diphenylphosphinic chloride (entry 1), chlorodicyclohexylphosphine (entry 2), phenyl and methyl disulfides (entries 3 and 4), diphenyl selenide (entry 5) and benzophenone (entry 6) as electrophiles all resulted in high diastereoselectivity. In almost all cases the major isomer was obtained readily as a single diastereoisomer following $\mathrm{SiO}_{2}$ column chromatography or recrystallization.

Scheme 5. Deuterium directed synthesis of $\left(S, R_{\mathrm{p}}\right)-{ }^{-}-d-\mathbf{y}^{-11}$ and $\left(S, S_{\mathrm{p}}\right)-5-d-\mathbf{1 2}$.

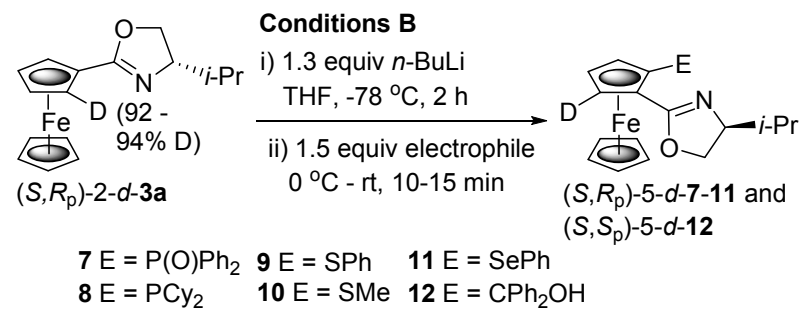

Table 3. Synthesis of $\left(S, R_{\mathrm{p}}\right)_{-5}^{-} d-\mathbf{- 7}-\mathbf{1 1}$ and $\left(S, S_{\mathrm{p}}\right)^{-5}-d-\mathbf{1 2}$.

$\begin{array}{ccccc}\text { entry } & \text { electrophile } & \text { product } & \begin{array}{c}\text { isomer } \\ \text { ratio }^{a, b}\end{array} & \begin{array}{c}\text { yield }(\%)^{c, d} \\ \left(\% \mathrm{D}^{\mathrm{a}, e}\right)\end{array} \\ 1 & \mathrm{ClP}(\mathrm{O}) \mathrm{Ph} 2 & \mathbf{7} & \mathbf{2 2 : 1} & 23(92) \\ \mathbf{2} & \mathrm{ClPCy2} & \mathbf{8} & 17: 1^{c} & 86^{f}(94) \\ 3 & \mathrm{PhSSPh} & \mathbf{9} & 12: 1 & 85(98) \\ 4 & \mathrm{MeSSMe} & \mathbf{1 0} & 13: 1 & 50(96) \\ 5 & \mathrm{PhSeSePh} & \mathbf{1 1} & 13: 1 & 61(96) \\ 6 & \mathrm{PhCOPh} & \mathbf{1 2} & 11: 1 & 68^{g}(94)\end{array}$

${ }^{a}$ Determined by ${ }^{1} \mathrm{H}$ NMR spectroscopy ( $500 \mathrm{MHz} \mathrm{CDCl}_{3}$ ). ${ }^{b}$ Determined before column chromatography unless otherwise stated. ${ }^{c}$ Determined after column chromatography $\left(\mathrm{SiO}_{2}\right) .{ }^{d}$ Diastereomerically pure unless otherwise stated. ${ }^{e} \mathrm{Of}$ major isomer. ${ }^{f}$ Obtained as a mixture of diastereoisomers ${ }^{g}$ Yield determined after recrystallization.

The diastereomeric bidentate ligands listed in Tables 2 and 3 have the potential to be applied in many metalcatalyzed asymmetric reactions. For such applications the incorporated deuterium blocking group may be regarded as being stereochemically invisible. When not broken as part of a reaction, the similarity between a C-D and a $\mathrm{C}-\mathrm{H}$ 
bond is illustrated by the former being only ca. $0.4 \mathrm{pm}$ shorter than the latter. ${ }^{13}$ Furthermore, the five-bond separation between deuterium and a metal coordinated by one of the bidentate ligands listed in tables 2 and 3 would appear to rule out the possibility of secondary isotope effects influencing catalyst activity and selectivity. ${ }^{14,15}$

Finally, that deuterium can be replaced in a subsequent reaction was illustrated by two procedures starting with $\left(S, R_{\mathrm{p}}\right)-5-d-5$ a that display C-D vs. C-Si selectivity (Scheme 6). Lithiation using conditions B, with $s$-BuLi substituted for $n$-BuLi, followed by addition of chlorodiphenylphosphine led to the isolation of silylated $\mathrm{N}-\mathrm{P}$ ligand $\left(S, S_{\mathrm{p}}\right)-\mathbf{1 3}$. $^{11}$ Also displaying this selectivity was cycloiridation with $\left[\mathrm{Cp}^{*} \mathrm{IrCl}_{2}\right]_{2}$ which resulted in iridacycle $\left(S, S_{\mathrm{p}}, S_{\mathrm{Ir}}\right)$-14 being formed as a single diastereoisomer. ${ }^{16}$ These uses of deuterium as a removable blocking group illustrate how this methodology enables the rapid stereoselective synthesis of multiple substituted ferrocene derivatives.

Scheme 6. Selective C-D vs. C-Si lithiation and cycloiridation.

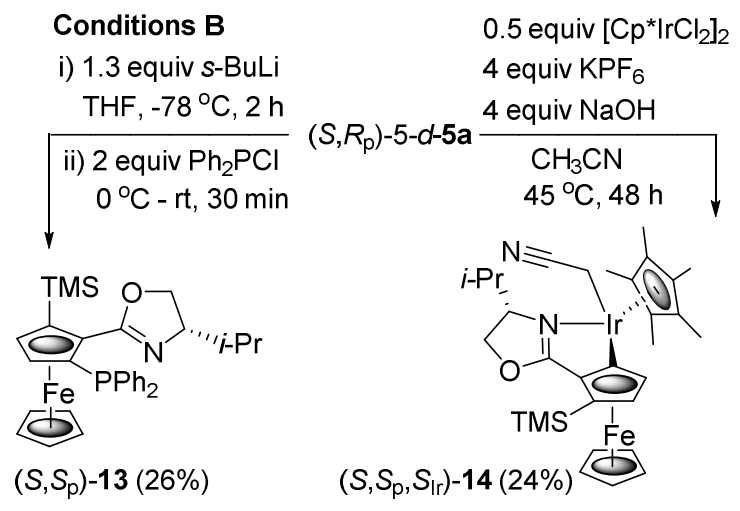

In conclusion, the combination of high and low diastereoselectivity resulting from $\mathrm{C}-\mathrm{H}$ lithiation, and the use of the high value of the primary kinetic isotope effect observed for C-D vs. C-H lithiation, provide the basis for largely reversing the diastereoselectivity of lithiation. This was exploited for the practical two-step synthesis of a series of ferrocenyloxazoline-based ligands, and extended to the synthesis of trisubstituted ferrocene derivatives.

\section{ASSOCIATED CONTENT}

\section{Supporting Information}

Experimental procedures and compound characterization data. This material is available free of charge via the Internet at http://pubs.acs.org.

\section{AUTHOR INFORMATION}

\section{Corresponding Author}

Chris.Richards@uea.ac.uk

\section{Author Contributions}

R.A.A. and C.J.R. contributed equally.

\section{Notes}

The authors declare no competing financial interest.

\section{ACKNOWLEDGMENT}

The AI-Chem Channel and the EPSRC (EP/No19393/1) are thanked for financial support. We also thank the EPSRC National Mass Spectrometry Centre (University of Wales, Swansea).

\section{REFERENCES}

(1) (a) Review: Muñiz, K.; Bolm, C. Chem. Eur. J. 200o, 6, 2309 For more recent examples in ferrocene ligand chemistry see: (b) Chen, W.; Mbafor, W.; Roberts, S. M.; Whittall, J. J. Am. Chem. Soc. 2006, 128, 3922. (c) Hu, X.-P.; Zheng, Z. Org. Lett. 2004, 6, 3585. (d) Chen, W.; Roberts, S. M.; Whittall, J.; Steiner, A. Chem. Commun. 2006, 2916. (e) Deng, W.-P.; You, S.-L.; Hou, X.-L.; Dai, L.-X.; Yu, Y.-H.; Xia, W.; Sun, J. J. Am. Chem. Soc. 2oo1, 123, 6508. (f) Schuecker, R.; Zirakzadeh, A.; Mereiter, K.; Spindler, F.; Weissensteiner, W. Organometallics 2011, 30, 4711. (g) Zirakzadeh, A.; Schuecker, R.; Gorgas, N.; Mereiter, K.; Spindler. F.; Weissensteiner, W. Organometallics 2012, 31, 4241.

(2) (a) Richards, C. J.; Damalidis, T.; Hibbs, D. E.; Hursthouse, M. B. Synlett 1995, 74. (b) Nishibayashi, Y.; Uemura, S. Synlett 1995, 79. (c) Richards, C. J.; Mulvaney, A. W. Tetrahedron: Asymmetry 1996, 7, 1419.

(3) Sammakia, T.; Stangeland, E. L. J. Org. Chem. 1997, 62, 6104 .

(4) (a) Ahn, K. H.; Cho, C.-W.; Park, J.; Lee, S. Tetrahedron: Asymmetry 1997, 8, 1179. (b) Ahn, K. H.; Cho, C.-W.; Park, J. Lee, S. Bull. Korean Chem. Soc. 1997, 18, 789. (c) Du, X.-D.; Dai, L.-X.; Hou, X.-L.; Xia, L.-J.; Tang, M.-H. Chin. J. Chem. 1998, 16, 9o. (d) Lautens, M.; Hiebert, S.; Renaud, J.-L. Org. Lett. 20oo, 2, 1971. (e) You, S.-L.; Hou, X.-L.; Dai, L.-X.; Cao, B.-X.; Sun, J. Chem.

Commun. 2ooo, 1933. (f) Kmentová, I.; Gotov, B.; Solcániová, E.; Toma, S. Green Chem. 2002, 4, 103. (g) You, S.-L.; Hou, X.-L.; Dai, L.-X.; Yu, Y.-H.; Xia, W. J. Org. Chem. 2002, 67, 4684. (h) Gosiewska, S.; Gotov, B.;Toma, S. Chem. Pap. 2oo4, 58, 113. (i) Cho, C.-W.; Son, J.-H.; Ahn, K. H. Tetrahedron: Asymmetry 2006, 17, 2240.

(5) Herbert, S. A.; Castell, D. C.; Clayden J.; Arnott, G. E. Org. Lett. 2013, 15, 3334 .

(6) (a) Hoppe, D.; Paetow, M.; Hintze, F. Angew. Chem., Int. Ed. Engl. 1993, 32, 394. (b) Clayden, J.; Pink, J. H.; Westlund, N., Wilson, F. X. Tetrahedron Lett. 1998, 39, 8377.

(7) (a) Knaus, G.; Meyers, A. I. J. Org. Chem. 1974, 39, 1192. (b) Jacobs, S. A.; Cortez, C.; Harvey, R. G. J. Chem. Soc., Chem. Commun. 1981, 1215. (c) Ahmed, A.; Clayden, J.; Rowley, M. Tetrahedron Lett. 1998, 39, 6103.

(8) Clayden, J.; Pink, J. H. Tetrahedron Lett. 1997, 38, 2565.

(9) In this Letter compounds that differ only by the presence or absence of deuterium have the same number. In all cases position 1 of the substituted cyclopentadienyl ring is attached to the oxazoline substituent. Planar chiral configurations are assigned by the Schlögl convention. See: (a) Schlögl, K.; Fried, M. Monatsh. Chem. 1964, 95, 558. (b) Schlögl, K.; Fried, M.; Falk, H. Monatsh. Chem. 1964, 95, 576.

(10) Ahn, K. H.; Cho, C.-W.; Baek, H.-H.; Park, J.; Lee, S. J. Org. Chem. 1996, 61, 4937.

(11) The modest yields are primarily due to phosphine oxidation. For these reactions diastereoselectivities were determined after preliminary $\mathrm{SiO}_{2}$ column chromatography as this procedure reduced oxidation of the target $\mathrm{P}-\mathrm{N}$ ligands to the corresponding 
phosphine oxides. Once isolated the phosphine ligands are stable to oxidation.

(12) Stark, M.; Jones, G.; Richards, C. J. Organometallics 2ooo, 19, 1282.

(13) Bartell, L. S.; Roth, E. A.; Hollowell, C. D.; Kuchitsu, K.; Young, J. E. Jr, J. Chem. Phys. 1965, 42, 2683.

(14) Both $\alpha$ and $\beta$ isotope effects have been reported for deuterated compounds. See: Perrin, C. L.; Ohta, B. K.;

Kuperman, J.; Liberman, J.; Erdélyi, M. J. Am. Chem. Soc. 2005, 127, 9641.

(15) That differentiation between $\mathrm{C}-\mathrm{H}$ and $\mathrm{C}-\mathrm{D}$ bonds can be significant is illustrated by the use of PhCHDOH ( $1.6 \mathrm{~mol} \%$, $>95 \%$ ee) as a chiral inducer for the Soai autocatalytic diisopropylzinc addition to 2-(tert-butylethynyl)pyrimidine-5carbaldehyde (product ee 95\%). See: Sato, I.; Omiya, D.; Saito, T.; Soai, K. J. Am. Chem. Soc. 20oo, 122, 11739.

(16) Arthurs, R. A.; Ismail, M.; Prior, C. C.; Oganesyan, V. S.; Horton, P. N.; Coles, S. J.; Richards, C. J. Chem. Eur. J. 2016, 22, 3065 . 